\title{
Frontières
}

\section{Une courte et très personnelle entrée en matière sur le droit de choisir}

\section{Marcel Boulanger}

Volume 20, numéro 1, automne 2007

La « bonne mort»

URI : https://id.erudit.org/iderudit/017957ar

DOI : https://doi.org/10.7202/017957ar

Aller au sommaire du numéro

Éditeur(s)

Université du Québec à Montréal

ISSN

1180-3479 (imprimé)

1916-0976 (numérique)

Découvrir la revue

Citer cet article

Boulanger, M. (2007). Une courte et très personnelle entrée en matière sur le droit de choisir. Frontières, 20(1), 99-99. https://doi.org/10.7202/017957ar d'utilisation que vous pouvez consulter en ligne.

https://apropos.erudit.org/fr/usagers/politique-dutilisation/ 


\section{Une courte et très personnelle entrée en matière sur le droit de choisir ${ }^{1}$}

\author{
Marcel Boulanger, M.D., \\ Association québécoise pour le droit de mourir \\ dans la dignité.
}

Je suis un médecin, diplômé en médecine depuis 1954, à qui cinquante ans d'exercice ont enseigné les limites de la médecine. À l'époque, la mort et la phase terminale qui la précédait n'étaient pas du domaine de la médecine - du moins on ne nous enseignait rien sur le sujet. Je me souviens sans fierté de ces patients à l'agonie que l'on isolait dans une chambre, porte fermée. La chambre était près du poste des infirmières, mais elle aurait pu être au bout du monde sans rien changer à l'état d'abandon dans lequel se trouvait le mourant.

Il faudra attendre longtemps avant de voir apparaître les soins palliatifs et ils ne sont pas encore généralisés, mais au moins il semble que la médecine ait compris que la mort et le mourir sont partie intégrante de la condition humaine et que, pour paraphraser le mot du poète, rien de ce qui est humain ne doit lui être étranger.

Thomas McKeown, dans son livre The Role of Medicine (1979), prévoit qu'avec une prévention efficace et tous les progrès actuels et à venir, ce rôle sera limité à aider à naître, réparer les os cassés ou usés et aider à mourir. Donc il ne faudra, dit-il, que des gynécologues-obstétriciens et des orthopédistes et il faudrait ajouter aussi des spécialistes de fin de vie.

Aux médecins de demain comme à ceux d'aujourd'hui se posera toujours la question de la mort digne, car il y aura toujours des cas où les soins palliatifs seront incapables d'assurer cette dignité.

Longtemps et lourdement, l'interdit religieux a eu force de tabou sur l'intervention de l'être humain sur sa propre mort. Le masochisme vu durant la vie comme comportement aberrant devient, avec le dolorisme, une voie salvatrice. Ici aussi une prise de conscience s'est effectuée mais beaucoup de chemin reste à parcourir.

Un rapide coup d'œil sur le chemin parcouru nous montre que grâce à Copernic et Galilée, on découvre que la Terre n'est pas le centre de l'univers, la planète et ses habitants tournent autour du Soleil et ne sont pas de simples jouets dans les mains d'une déité plus ou moins intransigeante. On commence à penser que si la planète doit obéir à des lois physiques auxquelles elle ne peut échapper, l'homme pour sa part a un certain contrôle sur sa destinée.

Pour Schopenhauer, l'homme vit dans la perpétuelle illusion de faire ses propres choix alors qu'il ne naît que pour assurer la survie de l'espèce et, une fois ce rôle rempli, la nature l'élimine sans aucun état d'âme. Sans nécessairement endosser cette vision cynico-pessimiste, si on jette un regard extrêmement schématique sur la destinée humaine, on retient ceci : on naît à la suite d'une décision prise par d'autres, sans aucune participation personnelle à cette décision, on se reproduit en réponse à des pulsions beaucoup plus instinctives qu'il n'y paraît en surface (voir les recherches sur le phénomène des phéromones) et, finalement, on meurt. Ce moment ultime, tout aussi capital que celui de sa naissance, est peut-être le seul où l'être humain, ce roseau pensant, a droit à un authentique pouvoir décisionnel.

Pour le croyant pascalien que je suis, qui a depuis longtemps cessé de croire à un Dieu justicier et sévère, l'injonction d'aimer son prochain comme soi-même n'est pas une invitation à la cruauté de laisser mon frère souffrir alors qu'il me demande de le soulager de sa condition humaine devenue irrémédiablement indigne et insupportable.

Dans certains cas, le maître de la vie et de la mort, Dieu lui-même, a besoin des hommes pour que sa miséricorde s'épanouisse. C'est ce à quoi je pensais quand j'ai écrit dans mon testament biologique.

«Si je devais jamais me trouver dans un état tel:

- Que mes fonctions cérébrales nobles (idéation, conscience de moi-même et des autres, capacité d'interrelation humaine) soient abolies sans espoir de récupération, je désire qu'on s'abstienne ou qu'on interrompe tout traitement incluant nutrition, hydratation et ventilation.

- Que suite à une maladie dégénérative (Alzheimer, par exemple), j'aie perdu mes capacités intellectuelles au point de ne plus reconnaître mes proches immédiats et ou que je sois devenu un être asocial non récupérable, je désire qu'on abrège mes jours par abstention de traitement, de soins nutritionnels et, si alors possible, par euthanasie.

Dans de telles circonstances, il s'agira d'un suicide médicalement assisté et celui ou celle qui m'aura prêté assistance ne sera criminel ni devant Dieu ni devant les hommes. »

\section{Bibliographie}

MCKEOWN, Thomas (1979). The Role of Medicine, Blackwell Editor.

\section{Note}

1. Frontières remercie Guy Lamarche et l'Association québécoise pour le droit de mourir dans la dignité qui nous ont autorisés à publier ce texte qui figure parmi les «Textes fondateurs» disponibles sur le site Web de l'association à l'adresse suivante: <www.aqdmd.qc.ca/texte. fondateur.Boulanger.html $>$. 